\title{
SASTRA LISAN DALAM PERKEMBANGAN TEKNOLOGI MEDIA; STUDI TERHADAP TRADISI SALAWAT DULANG DI MINANGKABAU
}

\author{
Eka Meigalia*), Yerri Satria Putra **) \\ Fakultas Ilmu Budaya Universitas Andalas, Padang, Indonesia \\ Email: ekameigalia@fib.unand.ac.id *) ; yerri@hum.unand.ac.id **)
}

Naskah diterima: 17 Sepetember; direvisi: 24 September; disetujui: 1 Oktober

\begin{abstract}
Abstrak
Tulisan ini menjelaskan kondisi sastra lisan ketika berhadapan dengan perkembangan teknologi media. Selain itu, juga dijelaskan pemanfaatan perkembangan teknologi serta media di era digital ini oleh para pelaku sastra lisan dalam proses kreatif mereka untuk keberlanjutan tradisi tersebut. Untuk itu, tradisi Salawat Dulang yang berkembang di Minangkabau dijadikan sebagai sumber data primer penelitian. Metode yang digunakan adalah metode kualitatif. Sedangkan teknik pengambilan data dilakukan dengan pengamatan, wawancara, serta kajian kepustakaan. Berdasarkan penelitian yang dilakukan, Salawat Dulang merupakan salah satu sastra lisan yang mampu bertahan karena kemampuannya untuk beradaptasi dengan perkembangan teknologi. Teks yang dituturkan selalu diperbaharui mengikuti selera masyarakat yang diperoleh penutur melelui media seperti televisi, radio, atau pun media sosial. Media sosial pun dijadikan oleh penuturnya sebagai sarana promosi dan publikasi kegiatan mereka dalam berkesenian.
\end{abstract}

Kata Kunci: kreatifitas, media, pewarisan, salawat dulang, sastra lisan, teknologi

\begin{abstract}
This paper explains the conditions of oral literature when dealing with the development of media technology. In addition, it explains the use of technologies and media developments in this digital era by oral literary actors in their creative processes for the continuity of tradition. For this reason, the tradition of salawat dulang which developed in Minangkabau was used as the primary data source for the study. The method in this research will be a qualitative. Meanwhile the technique of data collection is done by observation, interviews, and literature review. Based on the research conducted, salawat dulang is one of the oral literature that is able to survive because of its ability to adapt to technological developments. The text that is spoken is always updated according to the tastes of the people that are obtained by speakers through media such as television, radio or social media. Social media was used by speakers as a means of promotion and publication of their activities in the arts.
\end{abstract}

Keywords: creativity, media, inheritance, oral literature, salawat dulang, technology 


\section{Pendahuluan}

Manusia saat ini dikatakan tengah memasuki era di mana teknologi dan perangkat elektronik tidak bisa dilepaskan dari berbagai aspek kehidupan. Berbagai kegiatan yang dilakukan sehari-hari tidak lagi dilakukan secara manual, namun telah ada perangkat-perangkat elektronik yang membantu meringankan pekerjaan, seperti mencuci, memasak, membersihkan rumah, dan sebagainya. Begitu juga dengan berbagai keperluan dan kebutuhan hidup yang bisa diperoleh hanya dengan satu perangkat elektronik, yaitu ponsel cerdas (smartphone), seperti kebutuhan akan informasi, hiburan, belanja, makan, serta bepergian.

Menghadapi kemajuan teknologi tersebut, manusia dituntut untuk mampu secara efektif dan kritis menggunakan serta beradaptasi dengan berbagai kebaharuan yang muncul. Kemajuan teknologi dan informasi saat ini telah membawa perubahan yang positif bagi kehidupan manusia. Namun di saat yang sama, dampak negatif juga muncul sehingga menjadi tantangan baru di berbagai bidang kehidupan manusia, yaitu politik, ekonomi, sosial budaya, dan sebagainya (Eshet-Alkalai, 2004).

Dibidang budaya, perubahan dan tantangan sangat terasa terjadi pada tradisi masyarakat yang telah muncul jauh sebelum perkembangan teknologi dan media itu terjadi. Terutama sekali di bidang sastra lisan yang menurut Teeuw (1994) lahir dari masa ketika masyarakat belum mengenal aksara, pada masyarakat yang bercorak pedesaan. Ketika masyarakat telah memiliki banyak alternatif hiburan yang dapat diperoleh di mana saja dan kapan saja, maka salah satu fungsi dari sastra lisan, yaitu sebagai sarana hiburan, mulai berkurang bahkan menghilang. Akibatnya, satu persatu dari sastra lisan itu hilang dari masyarakat.

Minangkabau sebagai salah satu etnis yang memiliki ragam sastra lisan pun tidak luput mengalami perubahan tersebut. Tahun 1999, Amir dan kawan-kawan telah memetakan sastra lisan yang ada di Minangkabau dan menemukan setidaknya ada 30 jenis sastra lisan yang berkembang di wilayah budaya Minangkabau. Namun sebagiannya telah hilang atau punah dari tengah masyarakat pendukungnya (Amir, Adriyetti., 2006). Belum lagi di tahun-tahun terakhir ini, tentu telah semakin bertambah yang hilang atau pun terancam punah seperti
Basijobang yang sekarang hanya tinggal 2 orang penutur aktifnya dan belum ada pewarisnya, serta Tupai Janjang yang penutur satu-satunya baru saja meninggal tahun lalu tanpa ada yang mewarisi keahliannya.

Tentu banyak hal yang mempengaruhi perubahan atau hilangnya tradisi tersebut dari masyarakat. Terutama dengan semakin berkembangnya teknologi dan media saat ini. Beberapa bahkan menduga bahwa tradisi seperti sastra lisan ini akan sulit bertahan. Meskipun berbagai upaya telah dilakukan oleh berbagai pihak dalam rangka merevitalisasi tradisi-tradisi yang masih ada, namun beberapa telah terlanjur hilang. Tapi ada juga beberapa tradisi yang ternyata memiliki kemampuan untuk bertahan dan tetap disukai oleh khalayaknya. Salah satunya terjadi pada sastra lisan Salawat Dulang. Hingga saat ini, Salawat Dulang masih mudah ditemui, dipertunjukkan terutama sekali dalam rangka perayaan hari besar agama Islam. Begitu juga dengan penampilnya yang disebut dengan "tukang salawat". Grup-grup salawat baru masih terus bermunculan, bahkan yang beranggotakan anak-anak muda.

Menarik sekali membahas bagaimana kemampuan tradisi Salawat Dulang ini terus bertahan di tengah perkembangan teknologi media saat ini. Bertahan dan berupaya untuk tetap digemari oleh khalayaknya serta bersaing dengan berbagai alternatif hiburan dan medianya. Tetap memiliki fans setia tidak saja dari kalangan tua, namun juga muda. Tidak terbatas laki-laki atau pun perempuan. Oleh karena itu, tulisan ini akan memaparkan bentuk pemanfaatan teknologi serta media di era digital ini oleh para pelaku tradisi Salawat Dulang dalam pewarisan serta proses kreatif mereka demi mempertahankan keberadaan Salawat Dulang bagi khalayaknya.

Salawat Dulang merupakan tradisi yang cukup sering dibicarakan dalam berbagai tulisan ilmiah. Berkaitan dengan eksistensinya, Mardiani (2018) menjelaskan keberadaan tradisi Salawat Dulang di Padang Sibusuk, Kecamatan Kupitan, Kabupaten Sijunjung. Tradisi ini bertahan di tengah masyarakat karena masih memiliki fungsi bagi masyarakat. Salawat Dulang pun masih ditampilkan dalam berbagai upacara adat masyarakat setempat.

Sementara itu, Meigalia (2018) juga membahas model pewarisan tradisi Salawat Dulang dalam artikel yang diseminarkan di 
Seminar Antarbangsa Khazanah Melayu Serumpun dalam Era Baharu. Ada pun tahapan pewarisan tradisi Salawat Dulang yang dilalui oleh penampilnya terdiri atas tiga tahap, yaitu ketertarikan, mulai belajar, dan mendampingi guru dalam setiap pertunjukan.

Kedua tulisan tersebut sedikit
banyaknya menyinggung mengenai
keberadaan tradisi Salawat Dulang yang terus
bertahan di Minangkabau. Namun, terkait
dengan teknologi media dan bagaimana
kemampuan tradisi tersebut dalam
menghadapi perkembangannya justru belum
dibicarakan. Hal itulah yang menjadi fokus
penelitian dalam tulisan ini.

\section{Metode}

Penelitian untuk tulisan ini dilakukan dengan metode kualitatif. Sedangkan pengumpulan data dilakukan dalam beberapa tahapan, yaitu pengumpulan data, analisis, dan perumusan hasil analisis. Tahapan pengumpulan data dilakukan dengan beberapa teknik. Pertama adalah pengamatan. Pengamatan dilakukan di lapangan, dengan mengikuti beberapa pertunjukan Salawat Dulang. Pertunjukan tersebut memberikan informasi yang cukup besar terkait dengan popularitasnya dalam masyarakat. Khususnya dengan mengamati penonton dan aktifitasnya ketika pertunjukan Salawat Dulang berlangsung.

Pengamatan juga dilakukan melalui media social yang berkembang saat ini, yaitu youtube, facebook, dan instagram. Khususnya akun tukang salawat dan aktifitas mereka di media social terkait Salawat Dulang.

Pengumpulan data juga dilakukan dengan teknik wawancara. Tukang salawat serta penonton dan pecandu pertunjukan Salawat dulang adalah narasumbernarasumber yang dipilih. Wawancara pun dilakukan secara terbuka dan dapat diarahkan sesuai dengan kondisi di lapangan ketika wawancara berlangsung. Selain itu, pengumpulan data juga dilengkapi dengan penelusuran kepustakaan yang berhubungan dengan tradisi Salawat Dulang serta perkembangannya.

Tahapan penelitian selanjutnya adalah analisis terhadap data yang telah diperoleh. Terakhir penyajian hasil analisis dalam bentuk deskriptif.

\section{Hasil dan Pembahasan \\ 3.1 Sastra Lisan \\ Perkembangan Teknologi Media}

Ong (1982) membagi budaya lisan ke dalam dua tahapan. Pertama tahapan yang disebut dengan kelisanan primer, yaitu masa ketika masyarakat belum mengenal aksara dan yang berkembang hanyalah budaya lisan. Kemudian kedua disebut dengan kelisanan sekunder, yaitu tahapan ketika budaya lisan telah memasuki masa modern yang tidak saja bersentuhan dengan aksara, tapi juga media elektronik seperti televisi, radio, dan telepon. Memasuki masa kelisanan sekunder, kebudayaan lisan mendapat tantangan tersendiri dengan bermunculannya mediamedia elektronik tersebut. Pilihannya, tetap bertahan dan menyesuaikan diri, atau hilang karena tidak mampu bertahan serta menyesuaikan diri.

Sehubungan dengan hal itu, menurut Pudentia (2007), sastra lisan akan mengalami berbagai perubahan, diantaranya yaitu a) terancam punah atau telah punah karena fungsinya sudah berkurang atau berubah dalam kehidupan masyarakatnya; b) mengalami perubahan yang sangat lambat; dan atau c) berubah cepat sehingga tidak dikenali lagi bentuk awalnya. Dengan begitu, sastra lisan dapat dikatakan sebagai produk budaya yang dinamis, selalu mengalami perubahan dari waktu ke waktu. Berhadapan dengan perkembangan teknologi dan media, masyarakat mulai bergantung dengan berbagai peralatan elektronik yang memudahkan berbagai aktifitasnya. Berbagai hiburan baru pun bermunculan dengan media-media yang tidak membatasi manusia dengan ruang dan waktu. Salah satu akibatnya, sastra lisan pun mulai kehilangan khalayak fanatiknya sebagaimana yang dikemukakan Suryadi (2016) dalam penelitiannya terhadap Indang. Menurutnya, dahulu sastra lisan seperti indang begitu semarak karena adanya dukungan maesenas (para pendukung dan pelindung seni) yang mau tergila-gila dengan kesenian. Namun saat ini orang-orang seperti itu telah semakin langka. Tentunya hal tersebut juga akan berpengaruh terhadap kebelangsungan sastra lisan di tengah masyarakat.

Meskipun begitu, kemajuan teknologi media ternyata tidak pula sepenuhnya berdampak negatif berupa hilang atau punahnya sastra lisan dari masyarakat. Beberapa genre sastra lisan dapat mengikuti perkembangan tesebut dengan masuk ke 
industri rekaman sehingga bentuk pertunjukan atau tuturannya telah direkam dan dipasarkan. Berawal dalam bentuk piringan hitam gramofon, sastra lisan kemudian terus diterima dalam industri rekaman hingga ke kaset dan VCD. Untuk sastra lisan Minangkabau, Suryadi (2014) mencatat bahwa genre sastra lisan pertama yang masuk ke industri rekaman adalah Saluang Dendang yang direkam dalam bentuk piringan hitam gramofon pada tahun 1939. Kemudian rekaman sastra lisan dalam bentuk kaset muncul tahun 1971 yang merekam Rabab Pasisia. Hingga akhir tahun 90-an, rekaman berbentuk kaset masih terus diproduksi yang kemudian diiringi dengan rekaman berbentuk VCD mulai awal tahun 2000. Namun perlu digarisbawahi bahwa di Minangkabau, tidak semua genre sastra lisan masuk ke industri rekaman. Tetap saja kepopuleran diutamakan yang berdampak pada untung atau ruginya sebuah rumah produksi.

Khusus yang populer, hingga saat ini rekamannya masih terus diproduksi. Bahkan dengan adanya media sosial seperti youtube, facebook, instagram, dan lainnya, rekamanrekaman tersebut semakin disebarluaskan pemasarannya.

Dalam hal ini, kemajuan di bidang teknologi dan informasi telah turut andil untuk mempopulerkan dan membuat sastra lisan dapat dinikmati tidak terbatas ruang dan waktu lagi. Masyarakat dapat menikmatinya di ruang privat seperti di rumah melalui televisi, atau smartphone. Untuk kondisi tersebut, sastra lisan menjadi pertunjukan yang dapat terlepas dari penonton.

\subsection{Salawat Dulang dan Keberlanjutannya}

Salawat Dulang merupakan

pendendangan kisah, salawat, serta kajiankajian tarekat (khususnya syatariyah) dengan iringan irama tabuhan pada dulang. Dulang merupakan sejenis piringan logam besar berdiameter kurang lebih $30 \mathrm{~cm}$ yang terbuat dari kuningan. Biasanya digunakan untuk alas makan dalam kegiatan makan bajamba (bersama).

Dalam pendendangannya, tukang tutur yang disebut 'tukang salawat' berjumlah dua orang dalam satu grup. Dan dalam satu pertunjukan, terdapat dua grup yang akan saling mengajukan pertanyaan, menjawab, serta saling sindir. Setiap grup akan tampil secara bergantian dengan durasi masing- masing antara 40 menit hingga 1 jam. Pertunjukan yang biasanya dilaksanakan pada malam hari setelah salat Isya, akan berakhir beberapa saat menjelang waktu Subuh.

Gambar 1

Grup Salawat Dulang

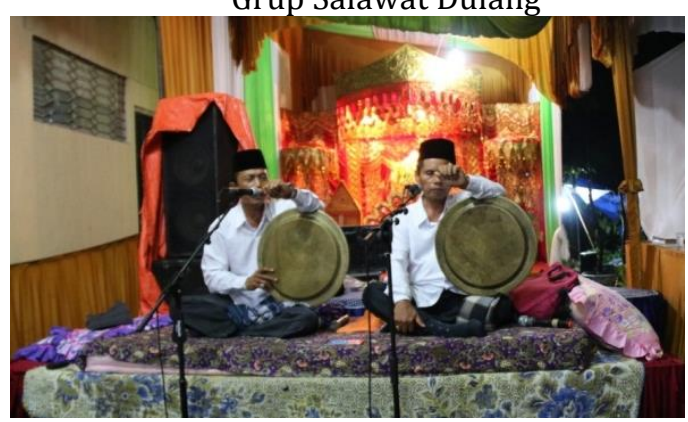

Sumber: dokumentasi pribadi

Tempat pertunjukan hanya diperbolehkan di dua tempat, yaitu tempat peribadatan umat Islam (mesjid atau musala) dan rumah. Tukang salawat pun saat tampil harus diberikan tempat duduk khusus yang disebut 'pale-pale'. Ditinggikan dari penonton dan diberi kasur. Masing-masing grup pun akan mendapat pale-pale sendiri sehingga saat menonton pertunjukan Salawat Dulang, selalu terdapat dua buah pale-pale.

Selain ditampilkan dalam rangka perayaan hari besar Agama Islam, Salawat Dulang juga dipertunjukkan dalam acara perkawinan meskipun sangat jarang ditemukan. Salawat Dulang juga akan dipertunjukkan dalam rangka alek nagari yang tujuannya menghimpun dana untuk pembangunan nagari. Sehingga tidak jarang dalam pertunjukan Salawat Dulang juga terdapat lelang makanan atau lagu.

Menurut sumber lisan, tradisi Salawat Dulang ini muncul pertama kali di kalangan kelompok Tarekat Syatariyah di Pariaman pada masa Syeh Burhanuddin mengembangkan ajaran Islam di sana. Namun versi lain menyebutkan tradisi ini muncul pertama kali di daerah Malalo, Kabupaten Tanah Datar yang juga di kalangan kelompok Terekat Syatariyah. Meski semula tradisi ini hanya dikembangkan dan ditampilkan di kalangan kelompok Syatariyah saja, lama kelamaan ditampilkan di muka masyarakat luas. Tukang salawat pun tidak pula dituntut harus berasal dari kalangan Syatariyah atau harus mempelajari ajaran Tarekat tersebut sebagaimana disampaikan oleh Firdaus pada wawancara tanggal 4 November di Kampung Pisang, Padang. Namun begitu, teks yang dituturkan tetap ada bagian yang membahas 
ajaran-ajaran tarekat seperti hakikat nyawa dan tubuh.

Dalam perkembangan teknologi media, Salawat Dulang pun telah ikut masuk ke dapur rekaman. Menurut catatan Suryadi (2010) rekaman pertama kali Salawat Dulang berbentuk kaset dari Grup Piriang Talayang dan Sahara yang membahas Kisah Nabi Ibrahim dan Pengorbanannya. Berikutnya, beberapa grup Salawat lainnya pun turut masuk industri rekaman, yaitu DC 8, Kilek Barapi, dan Arjuna Minang. Kemudian, rekaman dalam bentuk VCD pun mulai diproduksi di awal tahun 2000 dari Grup Arjuna Minang dan DC 8. Di awal tahun 2000 tersebut, rekaman VCD masih diproduksi berdampingan dengan kaset.Hingga saat ini, Salawat Dulang masih menjadi salah satu sastra lisan yang diproduksi serta dipasarkan rekaman-rekamannya dalam bentuk VCD. Sesuai dengan penelitian yang dilakukan Suryadi (2014), jika produser melihat bahwa rekaman tersebut digemari serta laku di pasaran, maka baik kaset atau pun VCD akan terus diproduksi. Artinya, Salawat Dulang adalah salah satu sastra lisan yang digemari oleh masyarakat dalam bentuk rekaman kaset atau pun VCD.

Disisi lain, dalam penelitian yang dilakukan tahun 2008 untuk mengamati perkembangan dan pewarisan tradisi Salawat Dulang ini, penulis menemukan fakta bahwa tradisi ini masih digemari baik oleh tua maupun kalangan muda. Pewarisannya pun masih terjadi dari senior kepada generasi yang lebih muda seperti yang terjadi pada grup Kilek Barapi. Grup Sinar Barapi ketika anggotanya yang telah memasuki usia senja pada akhirnya tidak aktif lagi tampil untuk memenuhi undangan. Namun ternyata anakanak mereka memiliki minat dan mau menjadi tukang salawat juga sehingga kemudian muncullah grup baru yang diberi nama Sinar Barapi yang beranggotakan Jon E.Rizal dan Ilham yang usianya masih terbilang muda ketika memulai bersalawat. Jon E. Rizal saja mengaku mulai bersalawat ketika masih kelas 6 SD, yaitu sekitar tahun 1982 dan kemudian masih aktif hingga sekarang.

Tahun 2017 yang lalu, penulis juga kembali mengamati pertujukan Salawat Dulang dan kembali mendapati fakta bahwa telah muncul pula grup-grup salawat baru yang beranggotakan anak muda. Bahkan, terakhir terdapat satu grup salawat yang terdiri dari anak-anak, yang bernama Grup
Bintang Cilik. Hal ini tentunya berbanding terbalik dengan genre sastra lisan lainnya yang sulit sekali bertahan, bahkan tidak memiliki pewarisnya lagi dari kalangan muda. Apalagi untuk menjadi sebuah pertunjukan yang digemari oleh penonton.

Secara umum, Salawat Dulang dapat dikatakan sebagai salah satu sastra lisan di Minangkabau yang mampu beradaptasi dengan perkembangan zaman. Mampu beradaptasi dengan berbagai alternatif hiburan yang ada agar tetap disukai oleh masyarakat. Kemampuan untuk menyesuaikan diri dari Salawat Dulang ini dapat dilihat dari beberapa aspek.

Pertama dari teks yang dituturkan.Secara garis besar, teks yang dituturkan dalam Salawat Dulang dapat dibagi atas katubah, lagu batang, yamolai, lagu cancang, panutuik. Bagian-bagian tersebut berbeda dari segi isi dan melodi membawakannya. Khusus bagian lagu batang dan lagu cancang (isi) merupakan bagian yang harus dihafalkan oleh tukang salawat. Untuk itu, mereka mendapatkannya melalui guru.

Sementara, bagian lain dari teks Salawat Dulang tidak perlu dihafalkan. Namun mereka gubah sesuai kreatifitas mereka saat pertunjukan berlangsung. Khususnya bagian hiburan, tukang salawat harus mampu membawakan lagu-lagu yang tengah popular di tengah masyarakat dengan gubahangubahan pada teksnya agar menjadi lucu. Kelenturan dari teks Salawat Dulang ini pula yang membuatnya mampu bertahan dan tetap diterima sebagai hiburan selain sebagai media pendidikan oleh masyarakat.

Untuk memiliki kemahiran serta kreatifitas yang baik dalam membawakan lagu-lagu populer, tukang salawat mengakui bahwa mereka harus mengikuti lagu-lagu yang tengah digandrungi oleh masyarakat. Menurut Jon E. Rizal (wawancara tanggal 28 Agustus 2018 di Padang), dulu radio dan televisi merupakan sumber kreatifitasnya untuk membawakan lagu-lagu dalam bersalawat. Kemudian ketika perkembangan teknologi semakin maju, khususnya dengan bermunculannya media sosial seperti youtube, facebook, instagram dan lainnya, ia pun memanfaatkannya menjadi pengikut yang bisa terbilang aktif.

Kreatifitas tersebut memang menyesuaikan diri dengan kemajuan zaman 
dan juga selera masyarakat. Seperti lagu "Taktuntuang" dari Upiak Isil yang saat ini tengah populer dibawakan oleh Grup Salawat Langkisau dengan gubahan teks sebagai berikut.

Aku belum mandi tak tuntuang tak tuntuang

Tapi cantik juga tak tuntuang tak tuntuang

Apalagi sudah mandi tak tuntuang tak tuntuang

Pasti baun cik jawi tak tuntuang tak tuntuang (Pasti bau tai sapi)

Ada gadis cantik yang lewat

Aku aniang je nyeh (diam saja)

Aku kode setek (sedikit)

Hai suit..suit...

Lagu yang dibawakan oleh Grup Langkisau tersebut ternyata mampu menghibur penonton, bahkan anak-anak yang turut tertawa karena mengenal lagu tersebut. Kemudian digubah sedikit agar menjadi lucu, maka semakin menariklah pertunjukan tersebut.

Berbeda lagi dengan lagu yang sama dibawakan oleh Grup Sinar Barapi berikut.

Aku belum mandi tak tuntuang tak tuntuang

Tapi masih gagah juga tak tuntuang

Apolagi kalau mandi tak tuntuang tak tuntuang

Pasti bantun katumba (bau ketumbar)

Kalau amak gaek (ibu tua) yang lewat

Aden maengeh saje(saya lengah saja)

Kalau apak gaek (bapat tua)nan (yang) lewat

Aden anok-anok saje(saya diam-diam saja)

Tapi kalau anak gadih nan (anak gadis yang) lewat

Aden mintak (saya minta) nomor hape

Kalau jando nan (janda yang) lewat

A pasti den kijok saje(saya kedip saja)

Jo diagiah kode(dan diberi kode)

Walau main sampai malam tak tuntuang tak tuntuang

Iyo lai baurang (ada orang) tak tuntuang tak tuntuang

Asal baco (baca) salawaik dulang tak tuntuang tak tuntuang

Dulang alah jadi gandang (dulang sudah jadi gendang)

Itu bana lah dek nyo dulang
Kutipan teks yang dilisankan Grup Sinar Barapi di atas terlihat berbeda dengan yang dibawakan oleh Langkisau meskipun sama-sama membawakan gubahan lagu "Taktuntuang". Kreatifitas tukang salawat disini diakui oleh Jon E.Rizal sebagai anggota Grup Sinar Barapi terbentuk dengan banyaknya melihat, mengamati, serta mengikuti media sosial.

Selain mengikuti media sosial, Firdaus dari Grup Arjuna Minang (wawancara pada 8 Oktober 2017 di Gaduik) bercerita bahwa kratifitas grup-grup salawat dalam membawakan lagu-lagu yang populer juga bisa direkam menggunakan hape. Rekaman tuturan dari grup lawan yang mereka biasanya dianggap menarik dan baru untuk kemudian mereka pelajari dan gubah lagi. Oleh karenanya akan muncul lagu yang sama dengan versi yang berbeda antar grup salawat seperti contoh lagu "Taktuntuang" di atas.

Kedua, dari kepopuleran grup salawat. Grup salawat hingga saat ini memang masih cukup banyak.Namun yang cukup aktif dan sering diundang ke berbagai tempat tidak banyak. Menurut Firdaus juga, grup yang populer dan sering ditemui dalam berbagai pertunjukan jumlahnya saat ini kurang lebih 10 grup. Untuk grup Arjuna Minang sendiri dalam sebulan bisa tampil minimal 4 kali. Jika sedang banyak kegiatan, mereka bisa tampil hingga 15 kali dalam satu bulan ke berbagai tempat.

Sementara itu, Grup Sinar Barapi dalam sebulan dapat bersalawat paling sedikit 5 kali. Grup ini lebih menarik lagi karena anggotanya, yaitu Jon E. Rizal menggunakan media sosial instagram, facebook, serta youtube untuk mempromosikan kegiatannya bersalawat. Selain sebagai tukang salawat, Jon E. Rizal juga dikenal sebagai penyanyi dan pencipta lagu Minang dengan nama panggung Jon Cakra. Ia memiliki akun instagram jhon_cakra dan jhoncakra. Di kedua akun tersebut, Jon E. Rizal tidak saja mempromosikan album dan lagu-lagu barunya, tapi juga kegiatan-kegiatannya bersalawat.

Selain instagram, Jon E.Rizal juga memiliki akun dan channel di youtube dengan nama John Cakra RR. Seperti juga di instagram, di youtube ini Jon E. Rizal juga mengunggah berbagai video lagu, serta pertunjukan salawat yang dilakukannya. Juga pertunjukan salawat dari Grup Bintang Cilik 
yang memang tengah dibinanya. Jon E. Rizal (wawancara tanggal 28 Agustus 2018 di Padang) mengatakan bahwa melalui media sosial tersebut, kepopulerannya bisa menjadi lebih luas lagi. Ia dikenal tidak saja oleh kalangan pencinta Salawat Dulang di Sumatera Barat, tapi bisa ditontong oleh siapa saja di belahan dunia mana pun. Dan itu menurutnya terbukti dengan masih cukup tingginya permintaan untuk tampil bagi grupnya.

Untuk teks yang dituturkan serta mempopulerkan grup, kemajuan teknologi serta informasi terlihat sangat berpengaruh terhadap keberlanjutan tradisi Salawat Dulang ini. Di sisi lain, Salawat Dulang pun merupakan tradisi yang sangat lentur. Ada bagian dari teks yang dapat digubah dan dikreasikan oleh tukang tutur menyesuaikan dengan selera khalayaknya. Dan ketika teks tersebut digubah dengan berbagai lagu yang tengah populer, tradisi itu tetap diterima sebagai Salawat Dulang. Bukan menjadi Salawat Dulang dangdut atau Salawat Dulang pop sebagaimana pada saluang dan rabab. Saat ini muncul istilah saluang dangdut dan rabab dangdut karena membawakan lagu-lagu dangdut.

\section{Simpulan}

Perkambangan teknologi serta media saat ini sangat berpengaruh pada keberlanjutan sastra lisan. Di Minangkabau, sastra lisan sebagiannya sudah hilang, dan sebagian lagi hampir hilang karena tidak ada pewarisnya dari generasi muda. Juga dikarenakan sastra lisan tersebut tidak mampu bersaing dengan bentuk hiburan lain yang tengah populer. Atau karena fungsinya sudah tidak ada lagi bagi masyarakat pendukungnya.

Berbagai permasalahan tersebut tidak terjadi pada Salawat Dulang. Salawat Dulang hingga saat ini masih sangat aktif dipertunjukkan. Masih banyak grup salawat yang ada, dan juga masih bermunculan yang baru, bahkan dari kalangan anak-anak. Keberlanjutan tradisi ini dan kemampuannya untuk bertahan salah satunya melalui adaptasi dengan kemajuan teknologi dan media yang ada. Dari segi teks yang dituturkan, tukang salawat selalu membawakan lagu-lagu yang tengah populer di tengah masyarakat. Tukang salawat pun memanfaatkan media seperti radio, televisi, serta smartphone dengan berbagai fiturnya untuk memperluas pengetahuan mereka.
Mereka akan membawakan lagu tersebut dengan versi gubahan mereka masing-masing.

Selain itu, kepopuleran grup juga mereka tingkatkan dengan menggunakan media sosial. Melalui media sosial, kegiatan bersalawat mereka unggah untuk diketahui dan dikenal oleh masyarakat yang lebih luas lagi. Dengan begitu, tradisi ini dapat dikatakan masih terus berlanjut seiring berkembangan zaman. Dan rasanya Salawat Dulang bukanlah salah satu tradisi dari masa lalu yang kondisinya dikhawatirkan akan hilang untuk beberapa waktu mendatang.

\section{Daftar Pustaka}

Amir, Adriyetti., D. (2006). Pemetaan Sastra Lisan Minangkabau. Padang: Andalas University Press.

Eshet-Alkalai, Y. (2004). Digital Literacy: A Conceptual Framework for Survival Skills in the Digital Era. Journal of Educational Multimedia and Hypermedia, 13(1), 93106.

Mardiani, Indah., D. (2018). Eksistensi Salawek Dulang Pada Masyarakat Padang Sibusuk Kecamatan Kupitan Kabupaten Sijunjung. E-Jurnal SenDraTasik, 7(I), 65-70.

Meigalia, E. dan Y. S. P. (2018). Model Pewarisan Sastra Lisan Salawat Dulang. In I. Zahid (Ed.), Khazanah Melayu Serumpun dalam Era Baharu (pp. 282290). Kuala Lumpur: PKKM.

Ong, W. J. (1982). Orality \& Literacy, The Technological of The Word. New York: Routledge.

Pudentia. (2007). Hakikat Kelisanan dalam Tradisi Lisan Melayu, Mak Yong. Jakarta: Asosiasi Tradisi Lisan.

Suryadi. (2010). The Impact of the West Sumatran Regional Recording Industry on Minangkabau Oral Literature. Wacana, 12(1), 1-30.

Suryadi. (2014). The Recording Industry and Regional Culture in Indonesia; The Case of Minangkabau. Universiteit Leiden.

Suryadi. (2016). Indang Pariaman; Masa Depan "Togue Fu" Terakhir di Minangkabau. Padang Ekspres.

Teeuw, A. (1994). Indonesia, Antara Kelisanan dan Keberaksaraan. Jakarta: Pustaka Jaya. 
Amir, Adriyetti., D. (2006). Pemetaan Sastra Lisan Minangkabau. Padang: Andalas University Press.

Eshet-Alkalai, Y. (2004). Digital Literacy: A Conceptual Framework for Survival Skills in the Digital Era. Journal of Educational Multimedia and Hypermedia, 13(1), 93106.

Mardiani, Indah., D. (2018). Eksistensi Salawek Dulang Pada Masyarakat Padang Sibusuk Kecamatan Kupitan Kabupaten Sijunjung. E-Jurnal SenDraTasik, 7(I), 65-70.

Meigalia, E. dan Y. S. P. (2018). Model Pewarisan Sastra Lisan Salawat Dulang. In I. Zahid (Ed.), Khazanah Melayu Serumpun dalam Era Baharu (pp. 282290). Kuala Lumpur: PKKM.

Ong, W. J. (1982). Orality \& Literacy, The Technological of The Word. New York: Routledge.

Pudentia. (2007). Hakikat Kelisanan dalam Tradisi Lisan Melayu, Mak Yong. Jakarta: Asosiasi Tradisi Lisan.

Suryadi. (2010). The Impact of the West Sumatran Regional Recording Industry on Minangkabau Oral Literature. Wacana, 12(1), 1-30.

Suryadi. (2014). The Recording Industry and Regional Culture in Indonesia; The Case of Minangkabau. Universiteit Leiden.

Suryadi. (2016). Indang Pariaman; Masa Depan "Togue Fu" Terakhir di Minangkabau. Padang Ekspres.

Teeuw, A. (1994). Indonesia, Antara Kelisanan dan Keberaksaraan. Jakarta: Pustaka Jaya.

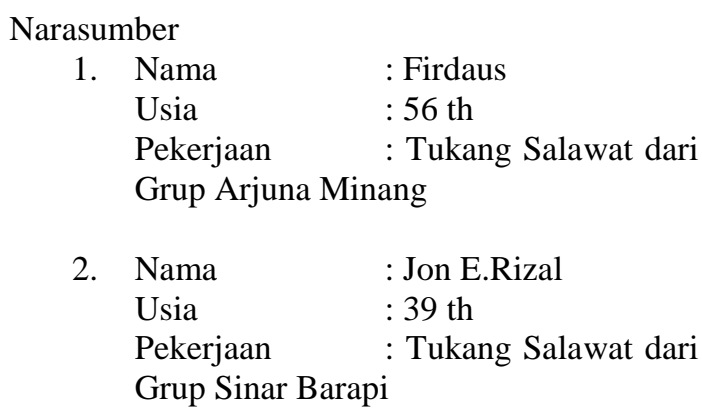

